\title{
Erratum to: Miniprobe endoscopic ultrasound accurately stages esophageal cancer and guides therapeutic decisions in the era of neoadjuvant therapy: results of a multicenter cohort analysis
}

\author{
Tobias Meister - Hauke Sebastian Heinzow - Regina Osterkamp • \\ Till Wehrmann - Torsten Kucharzik • Wolfram Domschke • \\ Dirk Domagk $\cdot$ Hans Seifert
}

Published online: 20 April 2013

(C) Springer Science+Business Media New York 2013

\section{Erratum to: Surg Endosc}

DOI 10.1007/s00464-013-2817-7

The correct order of authors should be Tobias Meister, Hauke Sebastian Heinzow, Regina Osterkamp, Till Wehrmann, Torsten Kucharzik, Wolfram Domschke, Dirk Domagk, Hans Seifert with Tobias Meister and Hauke Heinzow as equally first authors and Dirk Domagk and Hans Seifert as equally senior authors.

The online version of the original article can be found under doi:10.1007/s00464-013-2817-7.

T. Meister · H. S. Heinzow - R. Osterkamp - W. Domschke

D. Domagk

Department of Medicine B, Münster University Hospital,

Münster, Germany

T. Meister $(\bowtie)$

Department of Medicine II, Helios Albert-Schweitzer University

Teaching Hospital, Sturmbäume 8-10, 37154 Northeim,

Germany

e-mail: tobiasmeister@gmx.de

T. Wehrmann

Deutsche Klinik für Diagnostik Wiesbaden, Wiesbaden,

Germany

T. Kucharzik

Department of Medicine, University Teaching Hospital

Lüneburg, Lüneburg, Germany

H. Seifert

Department of Gastroenterology, Klinikum Oldenburg,

Oldenburg, Germany 